\title{
Sorsby's Fundus Dystrophy in the British Isles: Demonstration of a Striking Founder Effect by Microsatellite-generated Haplotypes
}

\author{
Sujeewa D. Wijesuriya, Kevin Evans, Marcelle R. Jay, ${ }^{1}$ Charles Davison, ${ }^{2}$ \\ Bernhard H.F. Weber, ${ }^{3}$ Alan C. Bird, ${ }^{1}$ Shomi S. Bhattacharya, and \\ Cheryl Y. Gregory ${ }^{4}$
}

Departments of Molecular Genetics and 'Clinical Ophthalmology, Institute of Ophthalmology, ${ }^{2}$ Department of Ophthalmology, Southampton General Hospital, Southampton, UK; ${ }^{3}$ Institute of Human Genetics, Würzburg, Germany

\begin{abstract}
Sorsby's fundus dystrophy (SFD) has been mapped to a genetic interval of $8 \mathrm{cM}$ between loci D22S275 and D22S278. A total of 15 families, unrelated on the basis of genealogy and expressing the SFD phenotype were identified from a large data base of genetic eye disease families originating from diverse parts of the British Isles. The identification of the same Ser181Cys mutation cosegregating with disease in each family led us to consider the hypothesis of a founder effect being present. In all families studied, the same relatively infrequent allele (occurring in just $11 \%$ of the control group) was associated with disease at marker locus D22S280. A highly significant disease-associated haplotype, spanning across $3 \mathrm{CM}$ of the SFD locus, was conserved in 11 of the 15 families ( $68 \%$ of all affected chromosomes); a further extended haplotype spanning up to $7 \mathrm{cM}$, was identified in 5 families (27\% of SFD-associated chromosomes) and possibly represents the ancestral haplotype. This haplotype analysis has refined the TIMP3 gene localization to a 1- to 3-cM interval between marker loci D22S273 and D22S281 and provides strong evidence for a single mutational event being responsible for the majority of SFD identified in the British Isles.
\end{abstract}

Sorsby's fundus dystrophy (SFD) is a fully penetrant, autosomal dominant retinal dystrophy (Sorsby and Mason 1949), characterized by the loss of central vision as a result of macular disease by the fourth to fifth decade and peripheral visual loss in late life. Histopathological studies show accumulation of material internal to the basement membrane of the retinal pigment epithelium, reaching as much as $30 \mu \mathrm{M}$ in thickness. Both clinically and histopathologically SFD shares some similarities with age-related macular degeneration (ARMD), a major cause of blindness in the developed world. The SFD locus was initially localized to chromosome 22q13-ter (Weber et al. 1994a) and subsequently refined to an 8-cM interval between loci D22S275 and D22S278 (Gregory et al. 1995). Two mutations, Tyr168Cys and Ser181Cys, of the gene encoding tissue inhibitor of metalloproteinases-3 (TIMP3), also mapping to 22q12.1-q13.2 (Apte et al. 1994),

${ }^{4}$ Corresponding author.

E-MAIL cgregory@hgmp.mrc.ac.uk; FAX 44-171-608-6863. have been shown to segregate with disease in two separate North American SFD pedigrees (Weber et al. 1994b). Recently, new SFD families with mutations in TIMP3 at codon Ser156Cys (Felbor et al. 1995) and codon Gly167Cys (Jacobson et al. 1995) have been described. TIMP3 is present in the extracellular matrix of various tissues and the presence of a TIMP-like protein recently has been reported in the interphotoreceptor matrix (Gallo et al. 1994). In SFD the TIMP3 protein may be directly or indirectly responsible for the deposition of material at the level of Bruch's membrane, which may subsequently lead to the manifestation of the SFD phenotype.

Data associating particular alleles of marker loci with disease phenotype can be used in the refinement of disease gene loci (Kerem et al. 1989; Bowcock et al. 1994). Such data may also be used to construct haplotypes of genomic regions inclusive of a disease locus. This has led to the identification of founder effects, with the diseasecausing mutation tracing back to a relatively small number of ancestors, in a number of stud- 
ies (Sirugo et al. 1992; Oudet et al. 1993; Petty et al. 1994). In this study we identify the same TIMP3 mutation and haplotype data in a relatively large number of SFD families, suggesting that a similar founder effect may be responsible for the majority of SFD identified in the British Isles. From these data we also infer a more precise genetic localization for the TIMP3 gene.

\section{RESULTS}

By direct sequencing and Nsil digestion the Ser181Cys mutation of TIMP3 was identified in all 76 affected members from the 15 SFD families included in the study. This mutation was seen to cosegregate with the disease phenotype across all families and was not present in any unaffected individuals or spouses (Figure 1). This evidence suggested that the Ser181Cys mutation could be the result of a founder effect.
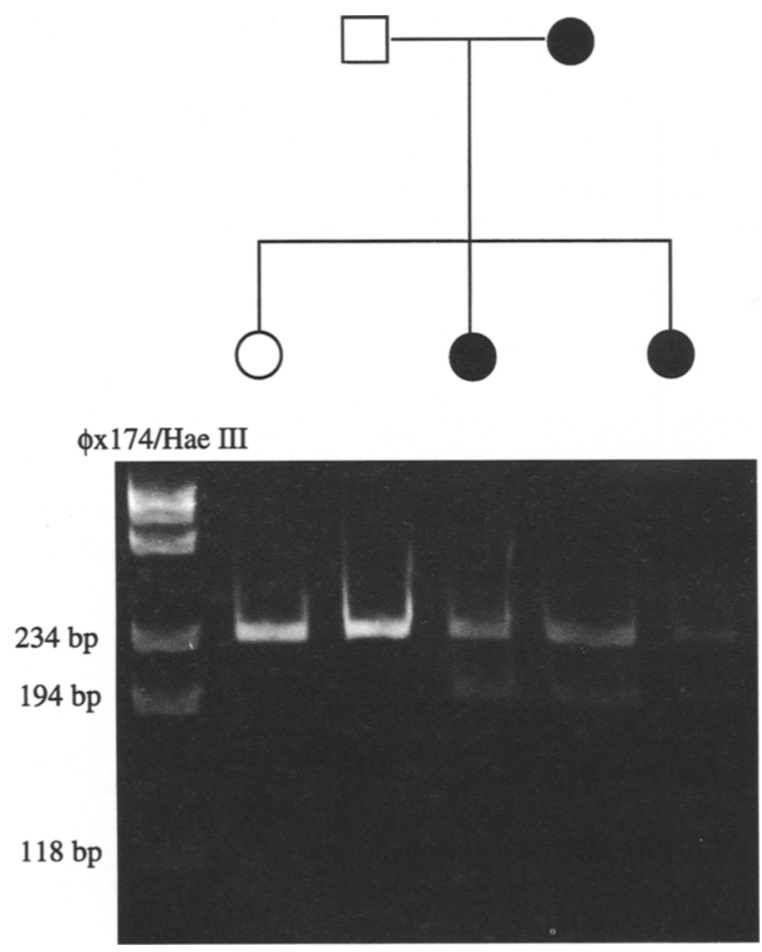

Figure 1 Cosegregation of SFD with the Ser181Cys mutation of TIMP3 in a branch of family 11. Nsil digestion of a PCR-amplified product of 240 bp results in two fragments of 200 and $40 \mathrm{bp}$ in affected individuals. The smaller 40-bp fragment is not seen in the ethidium bromide-stained $8 \%$ nondenaturing polyacrylamide gel depicted. All affected individuals are heterozygous for the mutation as both the 240 and 200-bp fragment are observed.

\section{FOUNDER EFFECI IN SORSBY'S FUNDUS DYSIROPHY}

\section{Allelic Association Studies}

All families were informative for all marker loci tested, and for each marker the disease bearing chromosome could be identified. Twenty-two different disease haplotypes and 54 control haplotypes ( 27 individuals) were compared by $\chi^{2}$ square and likelihood ratio test (LRT) analysis. Significant allelic association with disease was observed at marker loci D22S275, D22S273, D22S280, and D22S281, covering a 4-cM region (Table 1). Significant linkage disequilibrium estimated by Yules coefficient $(\delta)$ was observed between SFD and all of the above markers loci with the highest $\delta=1$ being observed with D22S275 and D22S280.

Table 1 presents allelic association data for normal and SFD chromosomes. The 176-bp allele of locus D22S275 was associated with disease in 9/22 (41\%) SFD chromosomes and was not represented in the normal control population. This association, however, reached significance with only the conventional $\chi^{2}$ analysis. Both statistical tests provided significant associations between the 198-bp allele of locus D22S273, $2 \mathrm{cM}$ distal to D22S275, which was present in $18 / 22$ (81\%) SFD chromosomes versus $15 \%$ normal chromosomes. Similarly the 218-bp allele of locus D22S280 and the 135-bp allele for locus D22S281, lying 2 and 3 cM distal to D22S273, respectively, accounted for $22 / 22(100 \%)$ and $18 / 22$ (81\%) SFD chromosomes and $11 \%$ and $20 \%$ normal controls, respectively. Using both statistical tests, these associations reached high levels of significance. Neither test provided significant associations between SFD and alleles of D22S278, a marker lying $4 \mathrm{cM}$ distal to D22S281. In the control population, alleles in addition to those published previously based on Centre d'Etude du Polymorphisme $\mathrm{Hu}$ main (CEPH) family data were identified at loci D22S275, D22S273, D22S280, and D22S281.

\section{Haplotype Association}

The 15 SFD families we studied were presumed unrelated even though some families came from the same area (Table 2), because they could not be linked by genealogy (See Subjects and Materials). Thus, we used microsatellite-generated haplotypes to try to establish a common lineage. Haplotypes segregating with the disease were constructed to identify a possible ancestral haplotype. Of a possible 43,200 haplotypes that could arise from the 5 tested markers, 160 were observed in our study population. The distribu- 
WIJESURIYA EI AL.

\begin{tabular}{|c|c|c|c|c|c|c|}
\hline \multirow{2}{*}{\multicolumn{2}{|c|}{$\begin{array}{l}\text { Marker and alleles } \\
\text { (size, bp) }\end{array}$}} & \multicolumn{2}{|c|}{$\begin{array}{c}\text { No. SFD } \\
\text { chromosomes (\%) }\end{array}$} & \multirow{2}{*}{$\begin{array}{l}\chi^{2}, \text { combined } \\
\text { allele method } \\
(P) \\
21 \\
(<0.0005)\end{array}$} & \multirow{2}{*}{$\begin{array}{l}\text { Yules } \\
\text { coefficient } \\
(\delta) \\
1\end{array}$} & \multirow{2}{*}{$\begin{array}{l}\text { LRT } \\
\text { (DISLAMB) } \\
(P) \\
13.3 \\
\left.1.3 \times 10^{-4}\right)\end{array}$} \\
\hline & & $\begin{array}{c}\text { affected } \\
9(41) \\
1(4)\end{array}$ & $\begin{array}{l}\text { normal } \\
\mathbf{0}(\mathbf{0}) \\
0(0) \\
8(15)\end{array}$ & & & \\
\hline D22S275 & $\begin{array}{c}1(176) \\
2(174) \\
3(172) \\
4(170) \\
5(168) \\
6(166) \\
7(164) \\
8(162) \\
9(160) \\
10(158)\end{array}$ & $\begin{array}{l}9(41) \\
1(4) \\
0(0) \\
3(13) \\
3(13) \\
4(18) \\
2(9) \\
0(0) \\
0(0) \\
0(0)\end{array}$ & $\begin{array}{c}\mathbf{0}(0) \\
0(0) \\
8(15) \\
14(26) \\
9(17) \\
9(17) \\
13(24) \\
0(0) \\
0(0) \\
1(2)\end{array}$ & $\begin{array}{l}21 \\
(<0.0005)\end{array}$ & 1 & $\begin{array}{l}13.3 \\
\left.1.3 \times 10^{-4}\right)\end{array}$ \\
\hline $\mathrm{D} 22 \mathrm{~S} 273$ & $\begin{array}{c}1(208) \\
2(206) \\
3(204) \\
4(202) \\
5(200) \\
6(198) \\
7(196) \\
8(194) \\
9(192) \\
10(190)\end{array}$ & $\begin{array}{c}0(0) \\
0(0) \\
0(0) \\
2(9) \\
0(0) \\
\mathbf{1 8 ( 8 1 )} \\
1(4) \\
1(4) \\
0(0) \\
0(0)\end{array}$ & $\begin{array}{c}1(2) \\
2(4) \\
1(2) \\
2(4) \\
1(2) \\
8(15) \\
19(35) \\
19(35) \\
0(0) \\
1(2)\end{array}$ & $\begin{array}{l}26.3 \\
(<0.0005)\end{array}$ & 0.93 & $\begin{array}{l}27 \\
\left(1.2 \times 10^{-7}\right)\end{array}$ \\
\hline $\mathrm{D} 22 \mathrm{~S} 280$ & $\begin{array}{l}1(222) \\
2(220) \\
3(218) \\
4(216) \\
5(214) \\
6(212) \\
7(210) \\
8(208)\end{array}$ & $\begin{array}{c}0(0) \\
0(0) \\
22(100) \\
0(0) \\
0(0) \\
0(0) \\
0(0) \\
0(0)\end{array}$ & $\begin{array}{c}1(2) \\
2(4) \\
6(11) \\
13(24) \\
10(18) \\
5(9) \\
11(20) \\
6(11)\end{array}$ & $\begin{array}{l}49.33 \\
(<0.0005)\end{array}$ & 1 & $\begin{array}{l}58 \\
\left(1.3 \times 10^{-14}\right)\end{array}$ \\
\hline $\mathrm{D} 22 \mathrm{~S} 281$ & $\begin{array}{l}1(149) \\
2(147) \\
3(145) \\
4(143) \\
5(141) \\
6(139) \\
7(137) \\
8(135) \\
9(133)\end{array}$ & $\begin{array}{c}0(0) \\
0(0) \\
0(0) \\
1(4) \\
1(4) \\
2(9) \\
0(0) \\
18(81) \\
0(0)\end{array}$ & $\begin{array}{c}3(6) \\
17(31) \\
2(4) \\
2(4) \\
9(17) \\
6(11) \\
2(4) \\
11(2) \\
2(4)\end{array}$ & $\begin{array}{l}22.5 \\
(<0.0005)\end{array}$ & 0.89 & $\begin{array}{l}22 \\
\left(1.5 \times 10^{-6}\right)\end{array}$ \\
\hline $\mathrm{D} 22 \mathrm{~S} 278$ & $\begin{array}{l}1(243) \\
2(241) \\
3(239) \\
4(237) \\
5(235) \\
6(233)\end{array}$ & $\begin{array}{l}0(0) \\
1(4) \\
6(27) \\
9(41) \\
6(27) \\
0(0)\end{array}$ & $\begin{array}{c}1(2) \\
1(2) \\
9(17) \\
29(54) \\
11(20) \\
3(6)\end{array}$ & $\begin{array}{r}1.6 \\
(0.2)\end{array}$ & 0.25 & $\begin{array}{l}0 \\
(0.5)\end{array}$ \\
\hline
\end{tabular}

SFD-associated allele is highlighted in bold.

tion of haplotypes on normal chromosomes was that expected from allele frequencies indicating linkage equilibrium between markers.
A predominant disease haplotype (alleles 6-3-8) for marker loci D22S273-D22S280D22S281 spanning $3 \mathrm{cM}$ was identified in 11 of 
15 families (68\% of SFD-associated chromosomes). Of the remaining seven SFD-associated haplotypes, six differed from the allele order 6-3-8 at a single locus (families 12, 13, 14, 5d, 5e, $2 \mathrm{~b}$; see Table 2 ). Family 15 only had one locus (D22S280) in common with all of the other Sorsby families. Assuming linkage equilibrium, the probability of observing the haplotype $6-3-8$ in the normal population is 0.15 $\times 0.11 \times 0.2=0.003(0.3 \%)$. Extension of this haplotype to encompass locus D22S275 identified a further preferential haplotype also exclusive to these SFD chromosomes, comprising the significantly associated alleles 1-6-3-8 (locus order D22S275-D22S273-D22S280-D22S281). This haplotype was present in five families (27\% SFD chromosomes).

Family 2 (Fig. 2) clearly shows maintainance of the ancestral haplotype in branch a of the family, whereas a recombination event in branch $b$ places the TIMP3 locus above D22S281 and thus in the 3 -cM interval between this locus and

\begin{tabular}{|c|c|c|}
\hline $\begin{array}{l}\text { Family } \\
\text { No: }\end{array}$ & Location & $\begin{array}{l}\text { Generations } \\
\text { traced }\end{array}$ \\
\hline 1 & Essex & 7 \\
\hline 2 & Buckinghamshire & 9 \\
\hline 3 & Greater London & 4 \\
\hline 4 & Warwickshire & 4 \\
\hline 5 & Buckinghamshire & 7 \\
\hline 6 & Cumbria & 12 \\
\hline 7 & Cumbria & 9 \\
\hline 8 & Cumbria & 7 \\
\hline 9 & Hampshire & 5 \\
\hline 10 & Greater London & 3 \\
\hline 11 & Merseyside & 8 \\
\hline 12 & Yorkshire & 6 \\
\hline 13 & Northamptonshire & 3 \\
\hline 14 & Eire & 7 \\
\hline 15 & Merseyside & 5 \\
\hline 16 & North American & 7 \\
\hline
\end{tabular}

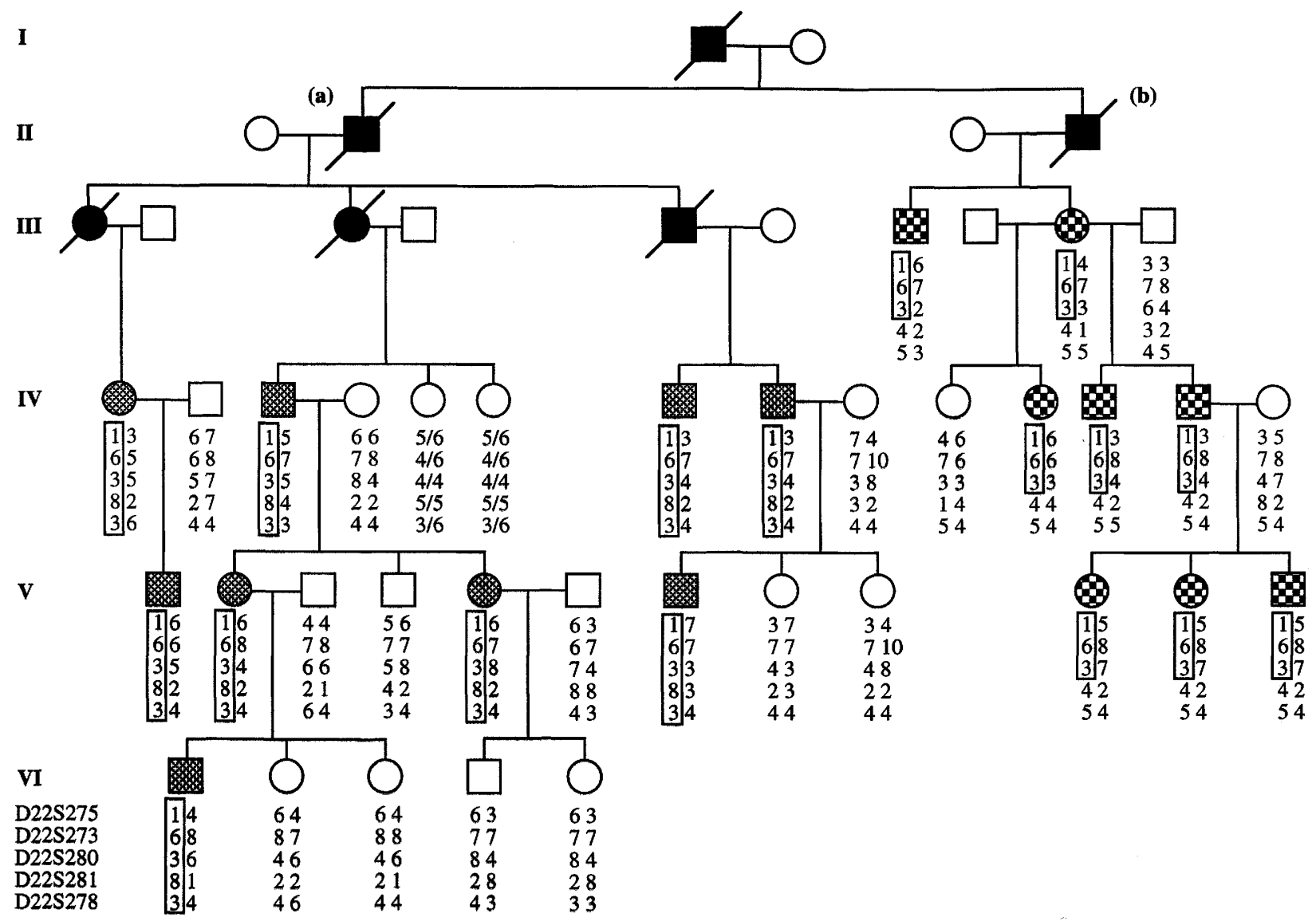

Figure 2 Segregation of marker loci in family 2 . Solid symbols signify affected patients. The haplotype segregating with SFD is boxed. Branch $a(\boldsymbol{\omega})$ is seen to carry the probable ancestral haplotype; branch $b(\boldsymbol{\omega})$ demonstrates a recombination event localizing the TIMP3 gene above D22S281; (W) affected individuals not haplotyped. Unknown phase is indicated by a slash between alleles. 


\section{WIJESURIYA ET AL.}

D22S273. The haplotype present in branch b was not observed in any other family. Further evidence supporting this localization is a single crossover event in an unaffected individual of family 8 (data not shown). This individual has inherited the affected chromosome from her mother below locus D22S281 and does not carry the Ser181Cys TIMP3 mutation.

For those families presenting more than one disease-associated haplotype, the haplotypes differing at just one locus by 2 bp were excluded, as it was possible that they may have resulted from replication slippage during meiosis and the haplotype in majority was taken into consideration. This enabled the number of SFD-associated haplotypes to be reduced to 17 . For example, in family 5 , five haplotypes, a, b, c, d, and e (Table 3 ), can be reduced to two, 1-6-3-8-3 $(a, b, c)$; and 1-6-3-6-5 (d, e). The common haplotype in family 6 is $6-6-3-8-5$ and in family 8 is $5-6-3-8-5 . \chi^{2}$ values calculated still produced highly significant allelic associations for the haplotype 1-6-3-8 and 6-3-8 (data not shown). The disease-associated haplotype was also compared to the North American family where the Ser181Cys mutation was originally described (family 16, Table 3 ). The SFD-associated haplotype 7-7-3-8-4 was exactly the same as family 14, which originated from Eire (Fig. 3).

\section{DISCUSSION}

The strongest piece of evidence supporting a founder effect in the British SFD study population is the shared Ser181Cys mutation in all affected individuals. Additionally, there are highly significant allelic and haplotype associations between SFD and chromosome 22q marker alleles. This suggests a founder effect rather than a mutation hot spot at codon 181. A mutation hot spot is not the likely mechanism for single-base substitutions in dominant disease, with achondroplasia being the only known exception (Bellus et al. 1995). Of the five highly polymorphic markers analyzed, four showed significant allelic associations with SFD. The most significant association was between allele 3 at locus D22S280 (Yules coefficient value $=1$ for linkage disequilibrium) suggesting that this marker locus lies in close proximity to the SFD locus. As expected, disequilibrium decreases with loci farther centromeric and telomeric than D22S280. However, a rise in linkage disequilibrium (Yules coefficient value $=1$ ) for allele 1 at locus D22S275 was seen.
This may be explained by the fact that this allele is absent in our control population. It cannot be attributable to its unique association with disease, as there exists a fairly random distribution of other D22S275 alleles in the SFD-associated haplotypes. In addition, the association of this allele with disease was found only to be significant using the conventional $\chi^{2}$ test.

To study haplotype associations in the 15 families, two different statistical methods were used. The likelihood ratio test has been suggested as an improvement on the more conventional $\chi^{2}$ analysis, by undertaking calculations on the basis of multiallelic loci rather than simplifying the data to diallelic systems. Both methods gave comparable results. The SFD chromosomes showed significant association with alleles 1-63-8 (marker order D22S275-D22S273-D22S280D22S281). Phylogenetic analysis (using Parsimony version 3.1.1) on all 15 SFD pedigrees suggested the 1-6-3-8 haplotype to be the founder haplotype (data not shown). The CA(n) microsatellite loci used in haplotype analysis have relatively high estimated mutation rates of $1 / 590$ (range $1 / 726$ to $1 / 450$ ) (Hastabacka et al. 1992), which can allow the appearance of new alleles on descendants of common ancestral chromosomes. This may explain why the founder haplotype is observed in only $27 \%$ of the SFD families when four markers are used. A predominant core haplotype consisting of alleles 6-3-8 (marker order D22S273-D22S280-D22S281) was found to be conserved in the vast majority of SFD chromosomes $(68 \%)$. This kind of conservation indicates identity by decent, which is further supported by the fact that these haplotypes are not present on nondisease chromosomes. On the basis of allele frequencies in the control population and assuming linkage equilibrium among these marker loci, we would have expected a frequency of $0.3 \%$ for the 6-3-8 haplotype. It is therefore clear that there is a striking over-representation of this core haplotype (68\%) in the SFD population studied.

Of the seven SFD-associated haplotypes that did not have the core 6-3-8 haplotype, one differed from the allele order 6-3-8 at a single locus (family 14). Here, allele 6 at D22S273 was replaced by allele 7 , which was 2 bp larger. Because it is possible that this 2-bp difference was attributable to replication slippage during meiosis rather than recombination, the percentage of SFD-associated haplotypes with alleles 6-3-8 could be increased to $73 \%$. Similarly, of the six remaining haplotypes, five differed from this pre- 
FOUNDER EFFECI IN SORSBY'S FUNDUS DYSTROPHY

\begin{tabular}{|c|c|c|c|c|c|}
\hline \multirow{2}{*}{$\begin{array}{l}\text { Family } \\
\text { no. }\end{array}$} & \multicolumn{5}{|c|}{ Marker loci and SFD-associated alleles } \\
\hline & $D 225275$ & $D 225273$ & $D 22 S 280$ & $D 2 S 281$ & $D 225278$ \\
\hline 1 & 18 & 6 & 3 & 8 & 3 \\
\hline 2 (a) & 1. & 6 & 3 & 8 & 3 \\
\hline 3 & 1. & 6 & 3 & 8 & 3 \\
\hline 4 & 1. & 6 & 3 & 8 & 3 \\
\hline \multirow[t]{3}{*}{5} & 1 & 6 & 3 & 8 & 3 \\
\hline & 1. & 6 & 3 & 8 & 4 \\
\hline & 2 & 6 & 3 & 8 & 3 \\
\hline \multirow[t]{2}{*}{6} & 6 & 6 & 3 & 8 & 5 \\
\hline & 6 & 6 & 3 & 8 & 4 \\
\hline 7 & 6 & 6 & 3 & 8 & 5 \\
\hline \multirow[t]{2}{*}{8} & 5 & 6 & 3 & 8 & 5 \\
\hline & 4 & 6 & 3 & 8 & 5 \\
\hline 9 & 4 & 6 & 3 & 8 & 4 \\
\hline 10 & 4 & 6 & 3 & 8 & 4 \\
\hline 11 & 7 & 6 & 3 & 8 & 4 \\
\hline \multirow{2}{*}{5} & 1 & 6 & 3 & 6 & 5 \\
\hline & 1 & 6 & 3 & 5 & 4 \\
\hline 2 (b) & 1. & 6 & 3 & 4 & 5 \\
\hline 12 & 5 & 4 & 3 & 8 & 2 \\
\hline 13 & 6 & 8 & 3 & 8 & 4 \\
\hline 14 & 7 & 7 & 3 & 8 & 4 \\
\hline 15 & 5 & 4 & 3 & 6 & 4 \\
\hline 16 & 7 & 7 & 3 & 8 & 4 \\
\hline
\end{tabular}

dominant allele order at single loci. Although these could be attributable to real recombination events, they could also be explained by mutations at microsatellite loci; thus, the percentage of SFD-associated haplotypes with alleles 6-3-8 could theoretically be as great as $95 \%$.

Evidence for the existence of a founder effect for the Ser181Cys mutation is thus demonstrated with significant linkage disequilibrium over a relatively large genetic distance. Strong linkage dis- equilibrium has been reported with polymorphisms up to 7-10 cM away from a diseaseassociated gene (Blumenfield et al. 1993; Glaser et al. 1995). The genetic distance over which linkage disequilibrium can be demonstrated is related to the number of generations since the origin of the mutation. The finding of linkage disequilibrium over a region of 3-4 cM suggests a relatively recent origin for the mutation in this study population. Family 6 has been traced back for 12 gen- 


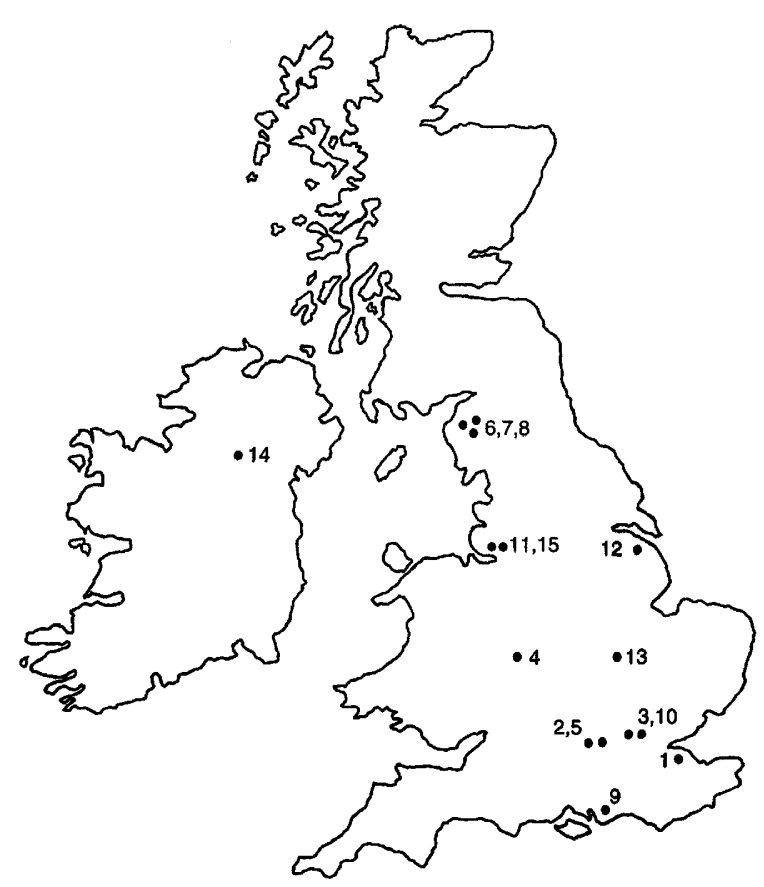

Figure 3 Distribution map of the birthplace of the earliest founder in each family. The solid circles mark the town of birth in the British Isles of the earliest member in each family that we could trace by genealogy. The numbers refer to family numbers.

erations to 1711 ( $~ 300$ years), suggesting the origin of the mutation to be earlier than this. In comparison, $650 \mathrm{~kb}$ of DNA in cystic fibrosis has been shown as the conserved segment of DNA for the founder effect seen in this disease, suggesting a much older mutation (Kerem et al. 1989).

SFD is a rare but well-characterized, blinding condition. The actual prevalence in the British Isles is unknown. For the purpose of the LRT analysis, which requires information on disease prevalence, SFD was presumed to have a prevalence rate of $1 / 100,000$. The data base of inherited eye disease families used constitutes the largest and best characterized available. We have contacted other UK registries and have not found any new SFD families. Although the 15 families and 76 affected individuals identified do not represents the total number, we propose that they constitute a significant proportion. The identification of a founder effect was unexpected for a number of reasons. The study group represents cases from disparate parts of the British Isles, a region known to be genetically diverse and heterogeneous with a long history of immigration from many parts of the world right up to the present day. For example, a proportion of families with the eye disease retinitis pigmentosa from our data base map to six different genetic loci. Also, because TIMP3 tissue expression is widespread (Wilde et al. 1994), the association with nonretinal disease in families 1,9 , and 11 was thought possibly to imply that each would express a different TIMP3 mutation. Interestingly, TIMP1 is expressed in gingival tissues of periodontitis patients (Meikle et al. 1994), and the relevance of a similar gum disease associated with TIMP3 needs to be investigated further. Similarly, TIMP1 activity has also been detected in the optic nerve head (Johnson et al. 1993), a region subject to glaucomatous damage. Therefore, a role for TIMP3 in a clinically distinct form of glaucoma is conceivable. However, the identification of the same mutation in all families suggests that these associations could now be considered either coincidental or related to the concurrent existence of other predisposing factors in those affected pedigrees.

Further study has also shown that the North American family in which the Ser181Cys mutation was originally identified (Weber et al. 1994b) possesses the same disease-associated haplotype as the family of Irish descent (family 14) and displays the alleles 3-8 for marker loci D22S280 and D22S281, respectively, as seen in our SFD families. Interestingly, genealogical evidence indicates this North American family is of Irish origin (Hamilton et al. 1989). It is therefore apparent that the Ser181Cys mutation of TIMP3 is the predominant SFD mutation within the British Isles; therefore, in all cases of suspected SFD, this mutation should form the basis for genetic screening in the United Kingdom. The nonradioactive NsiI digest technique described could therefore be the initial test in molecular genetic screening for this condition prior to direct sequencing. A simple, inexpensive, and reliable screening test such as this may be important, as the SFD phenotype can sometimes be clinically indistinguishable from other hemorrhagic maculopathies, a pathology common in the aging populations of the developed world. For example, in spite of a number of detailed clinical studies on family 6 , one individual clinically assessed as affected (see Fig. 3 in Polkinghorne et al. 1989), on repeated molecular genetic testing does not carry the Ser181Cys mutation or the disease-associated haplotype segregating in his family. It is therefore possible that phenocopies of maculopathies exist, which may be important to consider when genetically eval- 


\section{FOUNDER EFFECT IN SORSBY'S FUNDUS DYSTROPHY}

uating late-onset conditions such as SFD and ARMD.

\section{SUBJECTS AND MATERIALS Pedigrees}

A data base containing clinical information on $>4000 \mathrm{fam}$ ilies with different retinal dystrophies was accessed to identify SFD families. This data set has been documented over the last 25 years and contains families originating from throughout the British Isles, including England, Scotland, Wales, and Ireland. A total of 15 different SFD Caucasian families were found that were presumed unrelated from genealogical study (Table 2). The earliest founder member of each family that we identified was traced using a number of different sources available in the United Kingdom (Jay 1995), including civil registrations of births, marriages, and deaths, census returns, wills, and church parish records. For example, family 6 was traced back 12 generations to circa 1700 , yet we were unable to connect this family to any of the others. The number of generations traced in each family is presented in Table 2 , and the birthplace of the founder in each family is shown in Figure 3. Consanguinity was not observed in any of the families. From the SFD family set, 166 individuals were enrolled into the present study, including 76 affected individuals, 63 unaffected individuals, and 27 unrelated spouses. The inclusion criteria for affected status were that subjects were symptomatic by the fourth decade of life with progressive loss of visual acuity attributable to choroidal neovascularization or geographic atrophy. A prolonged choroidal filling phase on fluoroscein angiography was the earliest phenotypic marker observed, with later deposition of a confluent subretinal yellow material at the level of Bruch's membrane. These distinct features of the disease distinguish it from other clinical entities such as age-related macular degeneration and dominant drusen phenotypes. Detailed clinical data on three of these families (families 2, 6 , and 12) have been described elsewhere (Sorsby and Mason 1949; Polkinghorne et al. 1989). Additionally, nonretinal disease was seen to segregate significantly with the SFD phenotype in three families. Myotonic dystrophy in family 1 segregated over five generations, periodontitis in family 11 segregated over six generations, and pigment dispersion glaucoma in family 9 segregated over five generations (Evans et al. 1995).

\section{Mutation Detection}

Genomic DNA was extracted from EDTA blood samples according to standard procedures (Sambrook et al. 1989). For families 2, 6, and 11, DNA was available from members of four generations, whereas all others consisted of two generation pedigrees with at least two affected and one or two unaffected individuals. Initially, direct sequencing of exon 5 was performed for at least two affected and one unaffected individual per family. The Ser181Cys mutation creates a restriction site for the enzyme NsiI. However, the radioactive technique described previously to detect the Nsil site, amplifying a portion of exon 5, proved inefficient in our hands (Weber et al. 1994b). As an alternative, prim- ers amplifying the whole of exon 5 (Weber et al. 1994b) from genomic DNA were used. PCR reactions were carried out in $20-\mu 1$ volumes containing 100 ng of genomic DNA, $200 \mathrm{~nm}$ of each primer, $200 \mu \mathrm{m}$ each of dCTP, dATP, dTTP, and dGTP in $1 \times$ reaction buffer containing $1 \mathrm{mM} \mathrm{MgCl}_{2}$, and 0.2 units of $T a q$ polymerase. Thermal cycler settings were $94^{\circ} \mathrm{C}$ for $3 \mathrm{~min}$, followed by 32 cycles of $94^{\circ} \mathrm{C}$ for 45 $\mathrm{sec}, 55^{\circ} \mathrm{C}$ for $45 \mathrm{sec}$, and $72^{\circ} \mathrm{C}$ for $45 \mathrm{sec}$, followed by a final extension at $72^{\circ} \mathrm{C}$ for $5 \mathrm{~min}$. The resultant fragment was digested with $\mathrm{NsiI}$ at $37^{\circ} \mathrm{C}$ and separated on an $8 \%$ polyacrylamide nondenaturing gel. Fragments were then visualized using ethidium bromide rather than radioactivity. This method proved more sensitive and specific and thus is a better technique for a rapid screening protocol.

\section{Detection of Microsatellite Polymorphisms and Haplotype Analysis}

Individuals were genotyped by PCR using highly polymorphic CA(n) repeat microsatellites D22S275, D22S273, D22S280, D22S281, and D22S278 (Généthon map; Gyapay et al. 1994) closely linked to the SFD locus. Primers were end-labeled with $\left[\gamma_{-}{ }^{32} \mathrm{P}\right] \mathrm{dATP}(3000 \mu \mathrm{Ci})$ using $\mathrm{T}_{4}$ polynucleotide kinase. PCR reactions were carried out in 10- $\mu \mathrm{l}$ volumes as described in the mutation detection method above, except that $1.5 \mathrm{~mm} \mathrm{MgCl}_{2}$ was used and the annealing temperature varied from $55^{\circ} \mathrm{C}$ to $60^{\circ} \mathrm{C}$. The amplified products were resolved on $6 \%$ polyacrylamide sequencing gels containing $6 \mathrm{M}$ urea. Genotypes were ascertained after autoradiographic exposure.

Parental haplotypes for the microsatellite markers were examined to ensure correct assignment of disease haplotype, and in a few circumstances where DNA was unavailable from a parent, the haplotype data were inferred with the aid of siblings and other family members.

\section{Statistical Analysis}

One affected individual from each of the 15 families was selected for analysis; however, in families in which recombination events had occurred, two or more affected haplotypes were taken into consideration. Twenty-seven unaffected spouses contributed as controls for the assessment of allele frequencies, as these differed to the published frequencies in the CEPH families and for haplotype analysis. To test the null hypothesis of no association of marker alleles with disease (no linkage disequilibrium), the frequency distribution of alleles on disease- and nondiseasebearing chromosomes were analyzed across all families using two different statistical methods.

\section{$\chi^{2}$ Analysis Using a Combined Allele Method}

For each marker, this involved designation of the allele that was over-represented among SFD chromosomes as one allele, with the pooling of the remaining alleles to form a second allele. A standard $\chi^{2}$ test of independence was then calculated using a $2 \times 2$ contingency table with Yates correction at 1 degree of freedom (df). The degree of association was measured by Yules coefficient $(\delta)$ as demonstrated in Aksentijevich and co-workers (1993). 


\section{WIJESURIYA ET AL.}

\section{LRT for Linkage Disequilibrium}

This likelihood-based test was undertaken using the program DISLAMB (Terwilliger 1995), which accounts for markers with multiple alleles and calculates a simple likelihood ratio of association with appropriate $P$ values of significance.

\section{ACKNOWLEDGMENTS}

We thank Dr. Alex Morris for advice with statistical analysis, Dr. David Hunt for parsimony analysis, and all of the SFD families who participated in this study. This work was supported by Wellcome Trust grants $038650 / \mathrm{Z} / 93 \mathrm{Z} / 1.5 \mathrm{E} /$ REM/DK (to S.D.W.) and 043825/Z/95/A/WRE/MB/JAT (to C.Y.G.).

The publication costs of this article were defrayed in part by payment of page charges. This article must therefore be hereby marked "advertisement" in accordance with 18 USC section 1734 solely to indicate this fact.

\section{REFERENCES}

Aksentijevich, I., E. Pras, L. Gruberg, Y. Shen, K. Holman, S. Helling, L.Prosen, G.R. Sutherland, R.I. Richards, M. Dean, M. Pras, and D.L. Kastner. 1993. Familial Mediterranean fever (FMF) in moroccan jews: demonstration of a founder effect by extended haplotype analysis. Am. J. Hum. Genet. 58: 644-651.

Apte, S.S., M.G. Mattai, and B.R. Olsen. 1994. Cloning of the cDNA encoding human tissue inhibitor of metalloproteinase-3 (TIMP-3) and mapping of the TIMP-3 gene to chromosome 22. Genomics 19: 86-90.

Bellus, G.A., T.W. Hefferon, R.I. Ortiz de Luna, J.T. Hecht, W.A. Horton, M. Machado, I. Kaitila, I. McIntosh, and C.A. Francomano. 1995. Achondroplasia is defined by recurrent G380R mutations of FGFR3. Am. J. Hum. Genet. 56: 368-373.

Blumenfield, A., S.A. Slaugenhaupt, F.B. Axelrod, D.E. Lucente, C. Maayan, C.B. Liebert, L.J. Ozelius, J.A. Trofatter, J.L. Haines, X.O Breakefield, and J.F. Gusella. 1993. Localization of the gene for familial dysautonomia on chromosome 9 and definition of DNA markers for genetic diagnosis. Nature Genet. 4: 160-164.

Bowcock, A.M., J. Tomfohrde, J. Weissenbach, B. Bonne-Tamir, P. St. George-Hyslop, M. Giagheddu, L.L. Cavalli-Storza, and L.A. Farrer. 1994. Refining the position of wilson disease by linkage disequilibrium with polymorphic microsatellites. Am. J. Hum. Genet. 54: $79-87$.

Evans, K., C.Y. Gregory, S.D. Wijesuriya, M.R. Jay, A. Chopdar, and S.S. Bhattacharya. 1995. Molecular genetic studies of retinal dystrophies principally affecting the macula. In Retinal degeneration (ed. J.G. Hollyfield, R.E. Anderson, and M.M. LaVail), Plenum Press, London, UK. (in press.)

Felbor, U., H. Stöhr, T. Amann, U. Schönherr, and B.H.F.
Weber. 1995. A novel Ser156Cys mutation in the tissue inhibitor of metalloproteinases-3 (TIMP3) in Sorsby's fundus dystrophy with unusual clinical features. Hum. Mol. Genet. 4: 2415-2416.

Gallo, S., B.E. Jones, E. Thompson, P. Moshayedi, G. Chader, and R. Waldbillig. 1994. Characterization of a interphotoreceptor matrix metalloproteinase-TIMP-like inhibitor system. Invest. Ophthalmol. \& Visual Sci. 33: $1602-1648$.

Glaser, B., K.C. Chiu, R. Anker, A. Nestorowicz, N.J. Cox, H. Landau, N. Kaiser, P.S. Thornton, C.A. Stanley, E. Cerasi, L. Baker, H. Donis-Keller, and M.A. Permutt. 1995. Recombinant mapping of the familial hyperinsulinism gene to an $0.8 \mathrm{cM}$ region on chromosome $11 \mathrm{p} 15.1$ and demonstration of a founder effect in Askenazi jews. Hum. Mol. Genet. 4: 879-886.

Gregory, C.Y., S. Wijesuriya, K. Evans, M. Jay, A.C. Bird, and S.S. Bhattacharaya. 1995. Linkage refinement localises Sorsby's fundus dystrophy between markers D22S275 and D22S278. J. Med. Genet. 32: 240-241.

Gyapay, G., J. Morissette, A Vignal, C. Dib, C. Fizames, P. Millasseau, S. Marc, G. Bernardi, M. Lathrop, and J. Weissenbach. 1994. The 1993-1994 Genethon human genetic linkage map. Nature Genet. 7: 246-339.

Hamilton, W.K., C.C. Ewing, E.J. Ives, and J.D. Carruthers. 1989. Sorsby's fundus dystrophy. Ophthalmology 96: 1755-1762.

Hastbacka, J., A. de la Chapelle, I. Kaitila, P. Sistonen, A. Weaver, and E. Lander. 1992. Linkage disequilibrium mapping in isolated founder populations: Diastrophic dystrophy in Finland. Nature Genet. 2: 204-211.

Jacobson, S.G., A.V. Cideciyan, G. Regunath, F.J. Rodriguez, K. Vandenburgh, V.C. Sheffield, and E.M. Stone. 1995. Night blindness in Sorsby's fundus dystrophy reversed by vitamin A. Nature Genet. 11: $27-32$.

Jay, M.R. 1995. Ophthalmic genetics: a genealogical guide to sources in England and Wales. J. Med. Genet. 32: $946-950$.

Johnson, E.C., L.M.H. Deppmeier, A.C. Varner, and J.C. Morrison. 1993. Matrix metalloproteinases and TIMP1 in the primate optic nerve head and retina. Invest. Ophthalmol. \& Visual Sci. 34/4: 2406-2421.

Kerem, B.S., J.M. Rommers, J.A Buchanan, D. Markiewicz, T.K. Cox, A. Chakravati, and M. Buckwald. 1989. Identification of the cystic fibrosis gene: Genetic analysis. Science 245: 1073-1080.

Meikle, M.C., R.M. Hembry, J. Holley, C. Horton, C.Y. McFarlane, and J.J. Reynolds. 1994. Immunolocalization of matrix metalloproteinases and TIMP1 (tissue inhibitor of metalloproteinase) in human gingival tissues from periodontitis patients. J. Periodont. Res. 29: 118-126. 
Oudet, C., H. von Koskull, A.M. Nordstrom, M. Peippo, and J.L. Mandel. 1993. Striking founder effect for the fragile X syndrome in Finland. Eur. J. Hum. Genet. 1: 181-189.

Petty, E.M., J.S. Green, S.J. Marx, R. Thomas Taggart, N. Farid, and A.E. Bale. 1994. Mapping the gene for hereditary hyperparathyroidism and prolactinoma (MENI burin) to chromosome 11q: Evidence for a founder effect in patients from Newfoundland. Am. J. Hum. Genet. 54: 1060-1066.

Polkinghorne, P.J., M.R.C. Capon, T. Berninger, A.L. Lyness, K. Sehmi, and A.C. Bird. 1989. Sorsby's fundus dystrophy, a clinical study. Ophthalmology

96: 1763-1768.

Sambrook, J., E.F. Frisch, and T. Maniatis. 1989.

Molecular cloning: A laboratory manual, 2nd ed. Cold Spring Harbor Laboratory Press, Cold Spring Harbor, NY.

Sirugo, G., B. Keats, R. Fujita, F. Duclos, K. Purohit, M. Koenig, and J.L. Mandel. 1992. Friedreich ataxia in Lousiana acadians: Demonstration of a founder effect by analysis of microsatellite generated extended haplotypes. Am. J. Hum. Genet. 50: 559-566.

Sorsby. A., and M.E.J. Mason. 1949. A fundus dystrophy with unusual features. Br. J. Ophthalmol. 33: 67-97.

Terwilliger, J.T. 1995. A powerful likelihood method for the analysis of linkage disequilibrium between trait loci and one or more polymorphic loci. Am. J. Hum. Genet. 56: $777-787$.

Weber, B.H.F., G. Vogt, W. Woltz, E.J. Ives, and C.C. Ewing. 1994a. Sorsby's fundus dystrophy is genetically linked to chromosome 22q13-qter. Nature Genet.

7: 153-161.

Weber, B.H.F., G. Vogt, R.C. Pruett, H. Stohr, and U. Felbor. 1994b. Mutations in the tissue inhibitor of metalloproteinases-3 (TIMP3) in patients with Sorsby's fundus dystrophy. Nature Genet. 8: 352-356.

Wilde, C.J., P.R. Hawkins, R.T. Coleman, W.B. Levine, A.M. Delegeane, P.M. Okamoto, L.Y. Ito, R.W. Scott, and J.J. Seilhamer. 1994. Cloning and characterization of human tissue inhibitor of metalloproteinases-3. DNA Cell Biol. 13: 711-718.

Received August 21, 1995; accepted in revised form January $16,1996$. 


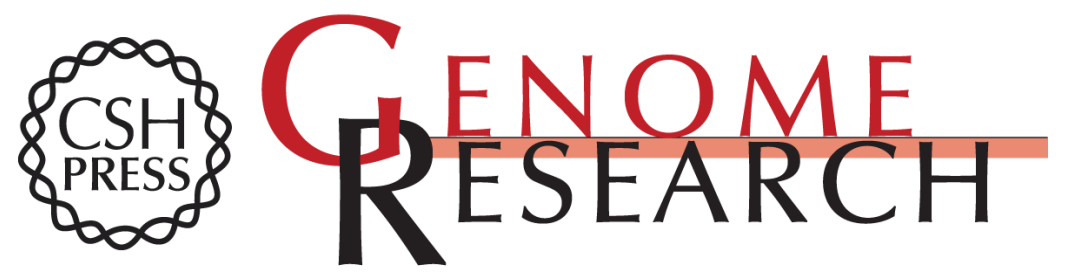

\section{Sorsby's fundus dystrophy in the British Isles: demonstration of a striking founder effect by microsatellite-generated haplotypes.}

S D Wijesuriya, K Evans, M R Jay, et al.

Genome Res. 1996 6: 92-101

Access the most recent version at doi:10.1101/gr.6.2.92

References This article cites 26 articles, 4 of which can be accessed free at:

http://genome.cshlp.org/content/6/2/92.full.html\#ref-list-1

\section{License}

Email Alerting Receive free email alerts when new articles cite this article - sign up in the box at the Service top right corner of the article or click here.

\section{Affordable, Accurate Sequencing.}

To subscribe to Genome Research go to:

https://genome.cshlp.org/subscriptions 